\title{
Isolation of teleost primordial germ cells using flow cytometry
}

\author{
RIE GOTO-KAZETO*,1,\#, TAIJU SAITO ${ }^{1,2 \#, ~ M I S A E ~ T A K A G I ~}{ }^{2}$, KATSUTOSHI ARAI ${ }^{2}$ and ETSURO YAMAHA ${ }^{1}$ \\ ${ }^{1}$ Nanae Fresh Water laboratory, Field Science Center for Northern Biosphere and \\ ${ }^{2}$ Faculty of Fisheries Sciences, Hokkaido University, Hakodate, Hokkaido, Japan
}

\begin{abstract}
Primordial germ cells (PGCs) generate gametes, the only cells that can transmit genetic information to the next generation. A previous report demonstrated that a fusion construct of green fluorescent protein (gfp) and zebrafish nos $13^{\prime}$ UTR mRNA could be used to label PGCs in a number of fish species. Here, we sought to exploit this labeling strategy to isolate teleost PGCs by flow cytometry (FCM), and to use these isolated PGCs to examine germ cell migration to the gonadal region. In zebrafish, medaka and goldfish, the PGCs were labeled by injecting the gfpnos 13 'UTR mRNA into 1- 4 cell embryos. When the embryos had developed to the somitogenesis or later stages, they were enzymatically disaggregated and GFP positive cells isolated using FCM. PGCs in the different species clustered in the same segments of the FCM scatter diagrams for total embryonic cells produced by plotting the forward scatter intensity against GFP intensity. In situ hybridization showed that the sorted zebrafish cells expressed vasa RNA in their cytoplasm, suggesting that they were PGCs. When the migration ability of the sorted cells from zebrafish was examined in an in vivo transplantation experiment, approximately $30 \%$ moved to the gonadal region of host embryos. These observations demonstrate that PGCs can be isolated without use of transgenic fishes and that the isolated PGCs retain the ability to migrate. Our data indicate that this technique will be of value for isolating PGCs from a range of fish species.
\end{abstract}

KEY WORDS: primordial germ cell, PGC, GFP, nos1, teleost, flow cytometry

\section{Introduction}

Primordial germ cells (PGCs) are the precursors of germ cells and are the only embryonic cells with the potential to transmit genetic information to the next generation. PGCs appear early in development and migrate autonomously through somatic cells toward the genital ridge. These developmental features can be exploited for the creation of germline chimeras by transplantation of PGCs. One newly established method, termed the single PGC transplantation method (SPT method), involves the transplantation of a single PGC into the blastoderm of a host embryo, that is, into the route of intrinsic PGC migration (Saito et al., 2008, 2010). The SPT chimeric embryos formed by this method have demonstrated that a single donor-derived PGC is sufficient for the construction of a germline chimera and for subsequent development of a functional gonad in zebrafish. This new approach to use of PGCs should open new fields for research and biotechnology in teleosts. However, it remains essential to develop an efficient means of mass isolation and purification of PGCs in order to expedite investigations into their biological properties.

The fundamental features of PGCs during embryogenesis are essentially conserved in teleosts although some slight differences in germ cell migration have been described among species (Saito et al., 2006). nanos1 (nos1), a gene expressed in germplasm and PGCs, is essential for the proper migration and survival of PGCs in zebrafish (Köprunner et al., 2001). The 3'UTR of nos 1 has been shown to be sufficient for directing the specific expression of the protein in the PGCs of zebrafish. In the course of investigating the migration pattern of PGCs in teleost species belonging to the orders Clupeiformes, Cypriniformes, Beloniformes, Percifomes and Pleuronictiformes, we found that gfp-zebrafish nos1 3'UTR mRNA could be used to visualize PGCs in a range of teleost species (Saito et al., 2006). This fluorescent cell-labeling method

Abbreviations used in this paper: FACS, fluorescence activated cell sorting; FCM, flow cytometry; GFP, green fluorescent protein; ISH, in situ hybridization; MACS, immunomagnetic cell sorting; PGC, primordial germ cell; SPT, single PGC transplantation method.

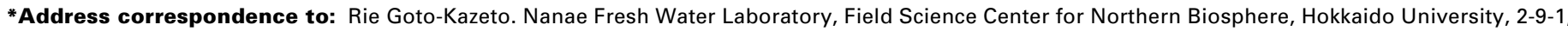
Sakura-machi, Nanae, Hokkaido 041-1105, Japan. Fax: +81-(0)138-65-2239. e-mail: goto-kazeto@hokudai-nanae.jp

\# Note: These authors contributed equally to this work 
has considerable potential for use in the automated isolation and purification of teleost PGCs.

Immunomagnetic cell sorting (MACS) and fluorescence activated cell sorting (FACS) have been used for the isolation and purification of PGCs in a wide array of animal species. In mammals and birds, successful isolation of PGCs by MACS was achieved using antibodies against cell surface markers expressed on the PGCs (Pesce and De Felici, 1995; Durcova-Hills et al., 1999-2000; Mozdziak et al., 2005). A small number of PGC cell surface markers are available for producing useful antibodies for this system. Unfortunately, as these PGC-specific cell surface markers have not been found in teleosts, MACS is currently not feasible in fish species. Isolation of PGCs using FACS has only been successful in a few species, principally because of the technical difficulties associated with the fluorescent labeling of the PGCs. One approach that has been successful is to use GFP-vasa transgenic lines that express GFP protein in the germline. This method has been applied to zebrafish (Fan et al., 2008), rainbow trout (Takeuchi et al., 2002) and Drosophila (Shigenobu et al., 2006), and has proved to be efficient for isolating PGCs. However, in teleosts, germline chimeras are not only useful for research into basic developmental biology but also for applied biotechnology (Yamaha et al., 2007). Therefore, development of a method for isolating PGCs from a range of species that avoids use of genetically modified organisms would be preferable for aquaculture research. Here, we demonstrate that these issues can be surmounted by utilizing gfp-zebrafish nos1 3'UTR mRNA.

The principal purpose of this study was to establish a method of isolating GFP-labeled teleost PGCs by flow cytometry (FCM). We used zebrafish as the model teleost species. Up until now, the established methods for isolating PGCs using fluorescent based cell sorting required either transgenic animals or specific antibodies for each sample. The method developed here avoids these technical complications by 1) no use of transgenic fishes, 2) no use of delicate surgical operations, such as the dissection of the genital ridge from hatching larvae. The efficiency of our new approach for isolating PGCs was confirmed by observation of isolated cells under a fluorescence microscope. These GFP positive cells were then verified as PGCs by in situhybridization (ISH) using vasa RNA expression. We tested the function of isolated PGCs by examining their ability to migrate toward the gonadal region in SPT chimeras. This FCM approach was also used successfully to isolate PGCs from goldfish and medaka embryos.

\section{Results}

\section{Flow cytometric analysis of PGCs}

One- to four-cell embryos were injected with gfp-nos1 3'UTR mRNA, allowed to develop to the somite stage, and disaggregated enzymatically. These embryos yielded fluorescently labeled PGCs
A

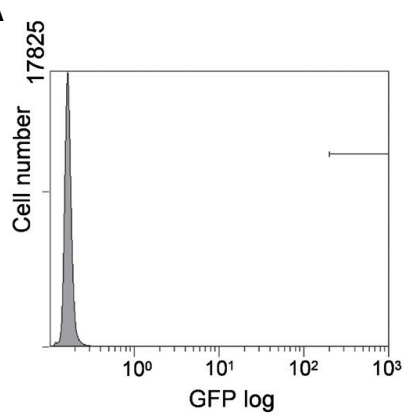

E zebrafish (20-25 somite stage)

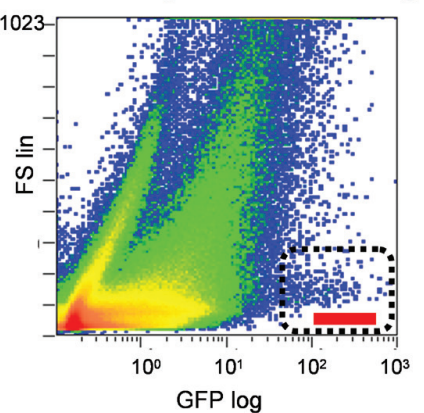

B

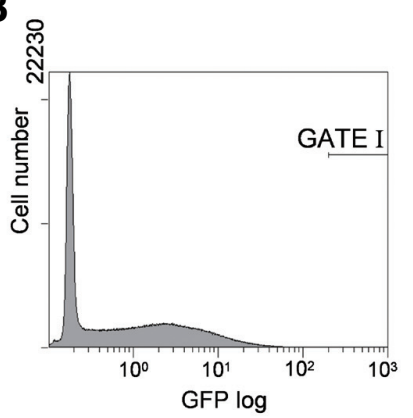

goldfish (20-25 somite stage)

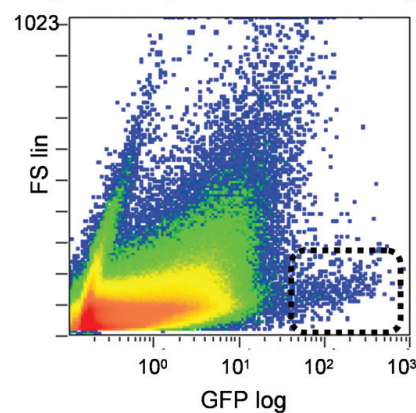

C

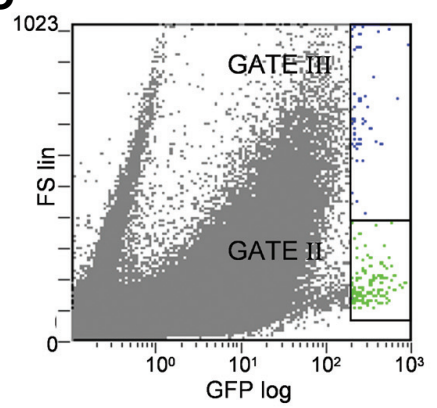

D

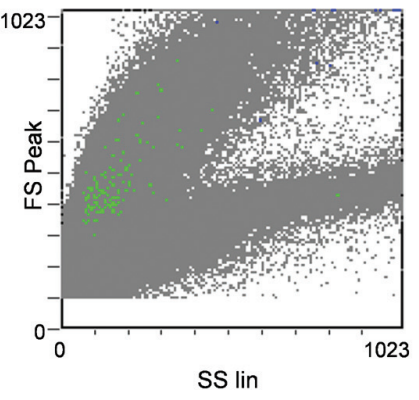

medaka (20-25 somite stage)

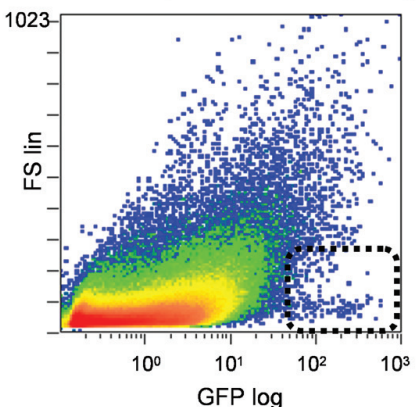

Fig. 1. Flow cytometric analyses of teleost embryonic cells. Flow cytometric data from cells from disaggregated 10-15 somite stage embryos (except E) were plotted using GFP intensity, forward light-scattering (FS) and side light-scattering (SS) properties. (A) Fluorescence intensity pattern in total unlabeled embryonic cells. (B) Fluorescence intensity pattern in cells labeled by injection of gfp-nos 1 mRNA. Xaxis represents GFP intensity (logarithmic scale) and Y axis indicates cell counts (linear scale). Highest GFP intensity (Log 10² - Log 103) was gated as GATE I. (C) FS (linear scale) versus GFP intensity (logarithmic scale) of total embryonic cells. A cluster of GFP positive cells (GATE II) showed a lower FS; other GFP positive cells were gated as GATE III. (D) FS/SS scatter diagram of total embryonic cells were over plotted with GFP-positive cells detected in GATE II as green dots and those of GATE III as blue dots (D). Most of the GFP positive cells in GATE I/ were PGCs and those in GATE III were cell aggregates. (E) FS (linear scale) versus GFP intensity (logarithmic scale) diagrams of total embryonic cells prepared from 20-25 stage embryos of zebrafish, goldfish and medaka. The boxed area enclosed by the broken line indicates the location of the PGCs. Red line indicates the location of the $10 \mu \mathrm{m}$ fluorescent beads (Beckman-Coulter). 
TABLE 1

\section{FLOW CYTOMETRY AND RECOVERY DATA FOR PRIMORDIAL GERM CELLS ISOLATED FROM TELEOST EMBRYOS}

\begin{tabular}{lccccc} 
Species & Stage & No. of embryos & $\begin{array}{c}\text { Average no. of } \\
\text { labeled PGCs }( \pm \text { SD) }\end{array}$ & $\begin{array}{c}\text { No. of GFP- } \\
\text { positive cells* }\end{array}$ & $\begin{array}{c}\text { Recovery } \\
(\%)^{\star *}\end{array}$ \\
\hline Zebrafish & $10-15$ somite & 50 & $20.5 \pm 6.5$ & 261 & 26.1 \\
& $10-15$ somite & 50 & $18.1 \pm 5.9$ & 243 & 27.0 \\
& $15-20$ somite & 30 & $23.9 \pm 8.8$ & 229 & 31.9 \\
Goldfish & $10-15$ somite & 27 & $30.4 \pm 13.9$ & 819 & 25.5 \\
& pigmentation & 30 & $29.0 \pm 13.4$ & 869 & 35.2 \\
Medaka & $20-25$ somite & 13 & $23.1 \pm 10.7$ & 124 & 41.3 \\
\hline
\end{tabular}

* Number of GFP-positive cells (presumptive PGCs) in GATE II determined by FCM.

** Percentage of GFP-positive cells in GATE II against total number of PGC in sample tube.

that could be sorted by FCM (Fig. 2A). The intensity of GFP fluorescence was clearly higher in cells from embryos injected with gfp-nos1 mRNA (Fig. 1B) than their untreated counterparts (Fig.1A). The cell population with a GFP fluorescence activity between $\log 10^{\circ}-\log 10^{2}$ in Fig. 1B contained cells with weak GFP fluorescence, which was observed as a background in embryos injected with gfp-nos1 3'UTR mRNA (Fig. 2A). Therefore, the intensity of GFP fluorescence in this cell population depended on the level of the fluorescence background in the embryos. Regardless of the intensity of the background, a small population of cells with the strongest GFP was present in the region (GATE I) between $\log 10^{2}$ and $\log 10^{3}$. The cells in the GATE I region of Fig. 1B were subdivided into two clusters (GATE II and GATE III in Fig. 1C) using the forward light-scattering (FS) channel versus GFP intensity (logarithmic scale). After sorting the
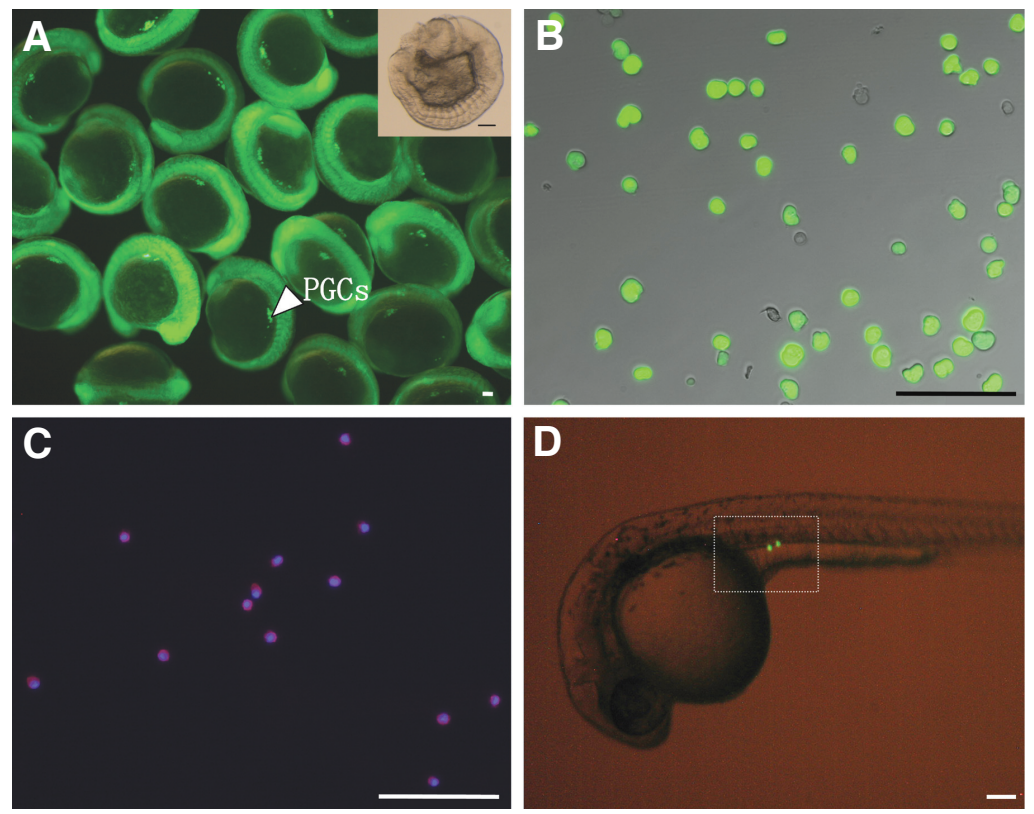

Fig. 2. Zebrafish primordial germ cells (PGCs) isolated from 10-15 somite stage embryos. (A) Zebrafish PGCs visualized by green fluorescence in a 15somite stage embryo that had been de-yolked. (B) Fluorescence microscopic image of PGCs isolated under the enrichment mode. (C) vasa RNA expression (red fluorescence) in isolated PGCs counterstained with DAPI (blue fluorescence). (D) Fluorescence micrograph of a day 1 zebrafish embryo transplanted with a single, sorted PGC. Scale bars indicate $100 \mu \mathrm{m}$. cells under the enrichment mode, the cells found in GATE II resembled PGCs in terms of size, shape and fluorescence levels (Fig. 2B). Microscopic analysis showed the highly fluorescent cells in the upper part of the FS channel (GATE III) to be cell aggregates. Furthermore, cells in GATE III were clearly distinguishable from those in GATE II when they were plotted using FS versus side light-scattering channels (Fig. 1D). The flow cytometric data obtained for goldfish and medaka embryos at the somite stage were similar to those from zebrafish (Fig. 1E). The boxed area in Fig. 1E enclosed by the broken line indicates the location of the PGCs, which were mostly above the position of the control beads. In medaka, the cluster of GFP positive cells appeared at a position indicating a relatively smaller size than in the other species (Fig. 1E).

The number of cells in GATE II was approximately $0.02-0.04 \%$ of the total number of embryonic cells screened by FCM in these three species. The numbers of labeled PGCs differed between teleost species and between embryonic stages, and recovery rates in the range $26-41 \%$ were achieved (Table 1 ).

\section{Verification and purity of derived PGCs in zebrafish}

To determine whether the sorted cells from GATE II consisted solely of PGCs, isolated cells were subjected to ISH using a vasa probe and were counterstained with DAPI. The vasa positive PGCs had a red fluorescence signal in their cytoplasm (Fig. 2C). For determination of the purity of the sorted cells, embryonic cells present in GATE II were sorted under either the enrichment or standard 3 modes with different pulse pile up (PPU) sensitivities (10-20 $\mathrm{usec}$ or $>20 \mu \mathrm{sec}$ ) (Table 2). The proportion of vasa positive cells ranged from $87.8 \%$ to $100.0 \%$ depending on the mode and sensitivity (Table 2). The 10-20 $\mu \mathrm{sec}$ PPU sensitivity setting resulted in the exclusion (abort category) of $93 \%$ of the cells that appeared in GATE II, whereas, only $33 \%$ were excluded at the $>20 \mu$ sec PPU sensitivity settting.

\section{Transplantation of sorted PGCs into zebrafish em- bryos}

A single sorted PGC, derived from embryos at the 10 15 somite stage, was transplanted into each zebrafish blastula. The transplanted PGC autonomously migrated to the genital ridge of the host embryos, which had been injected with $d n d-\mathrm{MO}$. Donor PGCs were present at the gonadal region of $31.5 \pm 1.8 \%$ of the host embryos (Table 3). The remainder of the embryos had a donor PGC located at various positions outside the gonadal region. In some of the host embryos, the transplanted PGC divided once after transplantation (Fig. 2D). There was no significant difference in the behavior of sorted PGCs and unsorted PGCs transplanted into host embryos $\left(\chi^{2}=\right.$ 0.461, $\mathrm{df}=1, \mathrm{P}<0.05)$ (Table 3).

\section{Discussion}

In this study, we developed a method for isolating PGCs from teleost embryos. The PGCs obtained by our protocol retained strong fluorescence after cell sorting. We transplanted a single PGC, sorted from 10-15 somite embryos, into the lower part of the blastoderm of each 
TABLE 2

\section{COMPARISON OF PURITY AND YIELD OF SORTED PGCS USING DIFFERENT SORTING MODE}

\begin{tabular}{|c|c|c|c|c|c|c|}
\hline \multirow[b]{2}{*}{$\begin{array}{l}\text { Sorting } \\
\text { mode }\end{array}$} & \multirow[b]{2}{*}{ Sorting function } & \multirow[b]{2}{*}{ PPU abort } & \multirow[b]{2}{*}{ Trial } & \multicolumn{3}{|c|}{ Number of cells } \\
\hline & & & & Sorted & Abort & $\begin{array}{c}\text { Vasa } \\
\text { positive (\%) }\end{array}$ \\
\hline \multirow[t]{4}{*}{ Enrichment } & $\begin{array}{l}\text { Low purity, } \\
\text { High yield }\end{array}$ & off & 1 & 106 & 0 & 81.0 \\
\hline & & & 2 & 110 & 0 & 90.0 \\
\hline & & & 3 & 101 & 0 & 92.3 \\
\hline & & & Total & 161 & 0 & $87.8 \pm 3.5$ \\
\hline \multirow[t]{4}{*}{ Standard 3} & $\begin{array}{l}\text { High purity, } \\
\text { Low yield }\end{array}$ & $10<,<20$ & 1 & 9 & 157 & 100.0 \\
\hline & & & 2 & 14 & 147 & 100.0 \\
\hline & & & 3 & 12 & 128 & 100.0 \\
\hline & & & Total & 35 & 432 & $100.0 \pm 0.0$ \\
\hline \multirow[t]{4}{*}{ Standard 3} & $\begin{array}{l}\text { High purity, } \\
\text { Low yeild }\end{array}$ & $20<$ & 1 & 111 & 68 & 99.1 \\
\hline & & & 2 & 107 & 39 & 100.0 \\
\hline & & & 3 & 79 & 42 & 100.0 \\
\hline & & & Total & 284 & 140 & $99.7 \pm 0.3$ \\
\hline
\end{tabular}

host embryo, and found that $31.5 \%$ of the transplanted cells retained the ability to migrate to the gonadal region in zebrafish. Thus, many of the PGCs that had been subjected to fluorescence labeling and cell sorting still retained the ability to migrate to the gonadal region.

Collagenase was used for disaggregation of embryos. Trypsin treatment $(0.5 \%)$, which has been used to separate PGCs from the genital ridge of rainbow trout embryos (Takeuchi et al., 2002), proved impractical here as the treated samples became viscous and blocked the flow line. This problem appears to arise with use of PGCs from somite stage embryos. Here, we used embryos at an earlier developmental stage than in the rainbow trout. We also found that the collagenase treatment was not enough to separate PGCs from other embryonic cells in later stage zebrafish embryos, e.g. prim-15, prim-25, or hatching stage (data not shown). Therefore, the identity and concentration of enzyme used to digest the embryos need to be optimized for each stage or species. Although removal of the yolk sac from embryos before digestion was not necessary for isolation of embryonic PGCs (data not shown), the yolk granules considerably increased the time needed for sorting as they were detected as cells by FMC. Moreover, the yolk granules may cause cell aggregation.

We have no means of assessing whether or not the recovery rate $(>25 \%)$ obtained in this study is high. Although higher recovery rates of $P G C$ isolation may be possible, it is not certain that this will not compromise the purity of the sorted PGCs. In the zebrafish, we found that an average of 21 cells per embryo were labeled following injection of gfp-nos 1 mRNA. However, the number of PGCs may vary between strains or with embryo stage. An average of approximately 50 PGCs at the genital ridge of intact embryos has been reported (Weidinger et al., 1999). Therefore, it is likely that the development and use of a more efficient labeling method may serve to raise the number of PGCs recovered. In this report, we have only shown data obtained from embryos at the 2025 somite stage in zebrafish, goldfish and medaka. Although there were slight differences in cell sizes and density between embryos at different somite stages and between species, nevertheless the PGCs always clustered in the lower right-hand segment of the scatter diagram produced by plotting FS versus GFP intensity.

ISH analysis of isolated PGCs was performed using a vasagene as probe. vasa is a marker of PGCs in vertebrates (Raz, 2000) and vasa RNA has been detected in the cytoplasm of PGCs of zebrafish embryos (Knaut et al., 2000; Yoon et al., 1997). The location of the vasa signals was found to change during early embryogenesis from a subcellular to cytoplasmic position; it was suggested that this change is correlated with the transition from use of maternal RNA to de novo synthesis (Knaut et al., 2000). In 30 hpf zebrafish embryos, which are presumed to equate to the prim-15 stage, vasa RNA was located in patches within the cytosol of PGCs. In this study, we were unable to identify the cellular location of vasa mRNA using the HNPP/Fast Red detection system in isolated

TABLE 3

\section{LOCATION OF TRANSPLANTED ZEBRAFISH PGCS, WHICH WERE ISOLATED USING A CELL SORTER} THEN TRANSPLANTED INTO BLASTULA STAGE EMBRYOS

\begin{tabular}{|c|c|c|c|c|c|c|c|}
\hline & \multirow[b]{2}{*}{ Group no. } & \multirow[b]{2}{*}{ Experimental group } & \multirow[b]{2}{*}{ Total no. of embryos } & \multirow[b]{2}{*}{ Number of normal embryos(\%) } & \multicolumn{3}{|c|}{ No. of embryos with PGC at ${ }^{\ddagger}$} \\
\hline & & & & & None (\%) & Germ ridge (\%) & Ectopic (\%) \\
\hline \multirow{8}{*}{$\begin{array}{l}\text { Donor PGC isolated } \\
\text { by cell sorter }\end{array}$} & \multirow{2}{*}{1} & Chimeras & 40 & $30(75.0)$ & $10(33.3)$ & $10(33.3)$ & $10(33.3)$ \\
\hline & & MO & 34 & $31(91.2)$ & - & - & - \\
\hline & \multirow{2}{*}{2} & Chimeras & 33 & $33(100.0)$ & $9(27.3)$ & $11(33.3)$ & $13(39.4)$ \\
\hline & & MO & 44 & $44(100.0)$ & - & - & - \\
\hline & \multirow{2}{*}{3} & Chimeras & 26 & $18(69.2)$ & $2(11.1)$ & $5(27.8)$ & $11(61.1)$ \\
\hline & & MO & 24 & $21(87.5)$ & - & - & - \\
\hline & \multirow{2}{*}{ Total $^{*}$} & Chimeras & 99 & $81(81.4 \pm 9.5)$ & $21(23.9 \pm 6.6)$ & $26(31.5 \pm 1.8)$ & $34(44.6 \pm 8.4)$ \\
\hline & & MO & 102 & $96(92.9 \pm 3.7)$ & - & & \\
\hline \multirow{8}{*}{$\begin{array}{l}\text { Donor PGC derived } \\
\text { from cell dispersed } \\
\text { solution }\end{array}$} & \multirow{2}{*}{1} & Chimeras & 37 & $37(100.0)$ & $7(18.9)$ & $13(35.1)$ & $17(46.0)$ \\
\hline & & MO & 37 & $37(100.0)$ & - & - & - \\
\hline & \multirow{2}{*}{2} & Chimeras & 20 & $20(100.0)$ & $1(5.0)$ & $7(35.0)$ & $12(60.0)$ \\
\hline & & MO & 24 & $23(95.8)$ & - & - & - \\
\hline & \multirow{2}{*}{3} & Chimeras & 17 & $14(82.4)$ & $2(14.3)$ & $4(28.6)$ & $8(57.1)$ \\
\hline & & MO & 24 & $15(62.5)$ & - & - & - \\
\hline & \multirow{2}{*}{ Total $^{*}$} & Chimeras & 74 & $71(94.1 \pm 5.9)$ & $10(12.7 \pm 4.1)$ & $24(32.9 \pm 2.2)$ & $38(54.3 \pm 4.3)$ \\
\hline & & MO & 85 & $75(86.1 \pm 11.86)$ & - & - & - \\
\hline
\end{tabular}

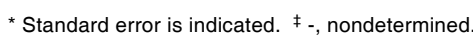


PGCs. However, variable patterns of vasa RNA distribution were observed in isolated PGCs derived from 10-15 somite embryos using NBT/BCIP staining (data not shown). Furthermore, ISH analysis proved that almost all the sorted cells were PGCs after isolation under standard 3 mode. During this period, there are dynamic changes in the PGCs: they undertake migration toward the genital ridge, and then lose their migratory ability; they settle and then proliferate in the genital ridge. The method of isolating PGCs should provide an assay for teleost PGCs and might help us to determine the staging of PGCs associated with cytological and developmental stages.

In order to test the function of isolated PGCs, we examined their ability to migrate toward the gonadal region. We transplanted a single PGC, sorted from embryos at the 10-15 somite stage, into each host blastula. In the three experiments, we observed a rate of $31.5 \pm 1.8 \%$ of host embryos with a donor PGC at the gonadal region; this rate is similar to that previously obtained for migration of unsorted PGCs to the host gonadal region in SPT chimeras (Saito et al., 2010). This indicates that the process of isolating PGCs in this study did not adversely affect the cells, for example, with regard to the expression of receptors on the cell surface that is necessary for migration. The isolation of PGCs from embryonic cells using FCM has one principal advantage over picking PGCs from a cell suspension prepared from disaggregated embryos: the FCM approach avoids the isolation of PGCs contaminated by attached somatic cells (such as from the gonadal soma). Therefore, generation of SPT chimeras using FCM-isolated PGCs enables investigation of cell-cell interactions during gonadal formation. In our hands, most of the SPT chimeras (95.2\%) generated a fully mature testis on one side of the body in zebrafish (data not shown). Thus, a donor sorted PGC can migrate to the gonadal region of a sterilized host embryo, and suggests that this chimera can produce $100 \%$ donor-derived gametes, as has been shown previously (Saito et al., 2008). The mechanism of PGC migration has been studied in many vertebrates (Molyneux and Wylie, 2004). It is thought that PGCs are specified early in development and are subsequently guided in their migration toward the genital ridge by signaling interactions with somatic cells. PGCs are believed to show changes to their morphology after reaching the genital ridge and to lose their ability to migrate. The relationship between PGC migratory ability and the developmental stage of the embryo has been examined using germline chimeras in zebrafish (Saito et al., 2010). The ability of PGCs to migrate to the genital ridge was lost as development proceeded such that PGCs derived from prim-25 stage embryos had almost completely lost the ability to migrate to the genital ridge. It is therefore possible that sorted PGCs will lose their ability to migrate to the genital ridge if the isolation process takes a long time.

In conclusion, zebrafish PGCs were successfully isolated by FCM and a protocol was established that was shown to be applicable to other teleost species. This method will make it possible to investigate many aspects of the biology of teleost PGCs that are currently obscure, such as their morphological and biochemical properties during migration.

\section{Materials and Methods}

\section{Preparation of embryos}

Stocks of zebrafish (Danio rerio), goldfish (Carassius auratus), and medaka (Oryzias latipes) were kept at the Nanae Fresh Water Laboratory,
Hokkaido University. Adult zebrafish were maintained at $27.5-28.5^{\circ} \mathrm{C}$ and their breeding condition controlled by a 16 hour light/8 hour dark (L16/D8) photoperiod. Zebrafish embryos were obtained by natural spawning. Dechorionation and incubation procedures were carried out as described by Nagai et al. (1999). In goldfish, we carried out artificial fertilization, developmental staging of embryos, dechorionation and incubation of embryos as described by Kajishima et al. (1960), Yamaha et al. (1986, 1998 and 1999) and Otani et al. (2002), respectively. Fertilized eggs of medaka were obtained by natural spawning at $26 \pm 0.5^{\circ} \mathrm{C}$ under an L16/D8 photoperiod. Incubation and staging of medaka embryos followed that of Iwamatsu (2004).

\section{Preparation and microinjection of gfp-nos 1 3'UTR mRNA}

A detailed description of the procedure for synthesis of the artificial mRNA is provided by Hashimoto et al. (2004). Briefly, a construct with the GFP open reading frame fused to the 3'UTR of zebrafish nos1 was prepared in a pCS2+ vector. MRNA was prepared using the mMESSAGE mMACHINE kit (Ambion, TX, USA) according to manufacturer's protocol and was purified using the RNeasy MinElute Cleanup Kit (QIAGEN, Tokyo, Japan). The mRNA was diluted with $0.2 \mathrm{M} \mathrm{KCl}$ to $300-350 \mathrm{ng} / \mu \mathrm{l}$. Fertilized zebrafish and goldfish eggs were dechorionated with $0.1 \%$ trypsin (zebrafish) or $0.1 \%$ trypsin and $0.4 \%$ urea in Ringer's solution (128 $\mathrm{mM} \mathrm{NaCl}, 2.8 \mathrm{mM} \mathrm{KCl}, 8 \mathrm{mM} \mathrm{CaCl}_{2}$ ) (goldfish). Dechorionated embryos were transferred to Ringer's solution supplemented with $0.01 \%$ penicillin and streptomycin. Then, gfp-nos1 3'UTR mRNA was microinjected into 1 to 4-cell stage embryos with a glass capillary needle and a microinjector (Eppendorf, Hamburg, Germany). Fertilized medaka eggs were collected in deionized water, and the mRNA was injected into the cytoplasm of eggs that had not been dechorionated. The embryos were maintained in culture until used for the FCM analysis.

\section{Preparation of embryonic cells for sorting}

After the blastula stage, GFP was expressed uniformly at a very low level. Different levels of expression were present in germ cells and somatic cells during the early gastrulation stages (Köprunner et al., 2001; Saito et al., 2006). Somite stage or pigmented embryos were used in each FCM experiment. Embryos were selected on the basis of showing similar intensities of PGC fluorescence. The embryos were placed in Ringer's solution and their yolk removed by excising the abdomen with fine forceps. Embryos were treated with $1 \mathrm{~mL} 200 \sim 400 \mathrm{U} / \mathrm{ml}$ collagenase (Wako Pure Chemical Industries, Ltd, Osaka, Japan) for $10 \mathrm{~min}$ at room temperature (RT). Individual cells from disaggregated embryos were separated from larger material using a $42 \mu \mathrm{m}$ nylon mesh filter just before cell sorting.

\section{Flow cytometric analysis and cell sorting}

The embryonic cells were passed across an argon laser at $488 \mathrm{~nm}$, with a $525 \mathrm{nM}$ filter to detect fluorescence (Beckman-Coulter EPICS ALTRA Flow Cytometer Cell Sorter, CA, USA). FS and SS from the cells were used for observation of the cell distribution profile. Fluorescent beads (10 $\mu \mathrm{m}$; Beckman-Coulter, Tokyo Japan) were used for optimization of the analyzer and cell sorting. To isolate PGCs, we identified subpopulations of cells based on their relative FS, SS and GFP intensities. These cells were gated and sorted under the enrichment or standard 3 modes with PPU option at $10-20 \mu \mathrm{sec}$ or $>20 \mu \mathrm{sec}$. According to the manufacturer's descriptions, the enrichment mode produces a relatively high yield of low purity, and the standard 3 mode a relatively low yield of high purity.

In situ hybridization with the zebrafish vasa probe on isolated cells

A probe for vasa mRNA was prepared as described by Hashimoto et al. (2004). Sorted cells were collected in PBS (+) supplemented with $0.05 \%$ FBS on slides pre-coated with $0.1 \%$ poly-L-lysine (Wako Pure Chemical Industries, Ltd, Osaka, Japan). Cells were aincubated in a hymid chamber at RT for 30 min. After confirming c 
freshly prepared $4 \%$ paraformaldehyde (PFA) in PBS onto the slides and fixed for $30 \mathrm{~min}$ at $4^{\circ} \mathrm{C}$. Cells were then washed in PBS and stored at $4^{\circ} \mathrm{C}$ in $70 \%$ ethanol until further processing. After washing with PBS, the cells were dehydrated through an ethanol series $(70,90$, and $100 \%$ ethanol), washed with xylene, rehydrated $(100,90$, and $70 \%$ ethanol), and then permeabilized with $0.5 \%$ TritonX-100 for $15 \mathrm{~min}$ at RT. They were next preincubated for $4 \mathrm{hr}$ at $42^{\circ} \mathrm{C}$ in hybridization solution (5XSSC, $50 \%$ formamide, $0.1 \%$ Tween $20, \mathrm{pH} 6.0,50 \mu \mathrm{g} / \mathrm{mL}$ heparin, $500 \mu \mathrm{g} / \mathrm{mL}$ yeast RNA). After prehybridization, we applied fresh hybridization solution containing labeled anti-sense probes $(250 \mathrm{ng} / \mathrm{mL})$ onto the slides. Hybridization was carried out overnight at $42^{\circ} \mathrm{C}$ and the slides were washed at high stringency. For signal detection, the HNPP fluorescent detection set (Roche Diagnostics, Tokyo, Japan) was used for staining, and the cells were counterstained with DAPI (100ng/ml). Blocking and detection steps were as described in the manufacturer's protocol. The signals were observed with a LEICA DMI 6000 fluorescence microscope and images were captured using a LEICA DFC350 FX CCD camera.

\section{Donor cell transplantation and hosts}

The viability of the sorted zebrafish PGCs was assessed by transplantation into zebrafish blastula-stage embryos using the SPT method (Saito et al. 2008). Briefly, host embryos were dechorionated in $0.1 \%$ trypsin (DIBCO) in Ringer's solution. The PGCs were sorted into a glass dish filled with Ringer's solution supplemented with $5 \%$ FBS. A single PGC was transplanted into the lower marginal part of the blastoderm of each embryo using a glass capillary needle and a microinjector (Eppendorf, Hamburg, Germany) under an Olympus SZX9 fluorescence microscope. Development of host PGCs was blocked by injection of a dead end ( $d n d)$ antisense morpholino oligonucleotide (MO) (Ciruna et al., 2002). Transplanted embryos were individually incubated at $28^{\circ} \mathrm{C}$ overnight in a 24 well plate filled with Ringer's solution containing $0.01 \%$ antibiotics. The rate of successful migration toward the gonadal region was determined at 1 day after transplantation. For the control group, SPT chimeras were generated using PGCs that had not been subjected to sorting.

\section{Statistical analysis}

The data on the migration rates of sorted and unsorted PGCs were statistically analyzed by the $\chi^{2}$-test. $P$-values $<0.05$ were regarded as significant.

\section{Acknowledgements}

The authors would like to express their gratitude to Mr. Yasuhiko Nagasaka from Beckman Coulter and Dr. Masaru Murakami from Azabu University School of Veterinary Medicine for their support with the cell sorting technique. We also thank Mr. Shizuo Kimura and the members of the Nanae Freshwater Laboratory, Field Science Center for Northern Biosphere, Hokkaido University for advice and help with breeding of the fish.

\section{References}

CIRUNA B, WEIDINGER G, KNAUT H, THISSE B, THISSE C, RAZ E, SCHIER AF (2002). Production of maternal-zygotic mutant zebrafish by germ-line replacement. Proc Natl Acad Sci USA 99: 14919-14924.

DURCOVA-HILLSG, TOKUNAGA T, KUROSAKAS, YAMAGUCHIM, TAKAHASHI S, IMAI H (1999-2000). Immunomagnetic isolation of primordial germ cells and the establishment of embryonic germ cell lines in the mouse. Cloning 1: 217224.

FAN L, MOON J, WONG T, CRODIAN J, COLLODI P (2008). Zebrafish primordial germ cell cultures derived from vasa::RFP transgenic embryos. Stem cells and development 17: 585-597.

HASHIMOTO Y, MAEGAWA S, NAGAI T, YAMAHA E, SUZUKI H, YASUDA K,
INOUE K (2004). Localized maternal factors are required for zebrafish germ cell formation. Dev Biol 268: 152-161.

IWAMATSU T (2004). Stages of normal development in the medaka Oryzias latipes. Mech Dev 121(7-8): 605-618.

KAJISHIMA T (1960). The normal developmental stage of the goldfish, Carassius auratus. Japan J Ichthyol 8: 20-28.

KNAUT H, PELEGRI F, BOHMANN K, SCHWARZ H, NÜSSLEIN-VOLHARD C (2000). Zebrafish vasa RNA but not its protein is a component of the germ plasm and segregates asymmetrically before germline specification. J Cell Biol 149: 875-888.

KÖPRUNNER M, THISSE C., THISSE B, RAZE (2001). A zebrafish nanos-related gene is essential for the development of primordial germ cells. Genes Dev 15: 2877-2885.

MOLYNEUX K, WYLIE C (2004). Primordial germ cell migration. Int J Dev Biol 48 537-544.

MOZDZIAK PE, ANGERMAN-STEWART J, RUSHTON B, PARDUE SL, PETITTE JN (2005). Isolation of chicken primordial germ cells using fluorescenceactivated cell sorting. Poult Sci 84: 594-600.

NAGAIT, YAMAHA E, ARAI K (1999). Histological differentiation of primordial germ cells in zebrafish. Zool Sci 18: 215-223.

OTANI S, MAEGAWA S, INOUE K, ARAI K, YAMAHA E (2002). The germ cell lineage identified by vas-mRNA during the embryogenesis in goldfish. Zool Sci 19: $519-526$

PESCE M. AND DE FELICE M (1995). Purification of mouse primordial germ cells by miniMACS magnetic separation system. Dev Biol 170: 722-725

RAZE (2000). The function and regulation of vasa-like genes in germ-cell development. Genome Biol 1: Reviews 1017.

SAITO T, FUJIMOTO T, MAEGAWA S, INOUE K, TANAKA M, ARAI K, YAMAHA $E$ (2006). Visualization of primordial germ cells in vivo using GFP-nos1 3'UTR mRNA. Int J Dev Biol 50: 691-699.

SAITO T, GOTO-KAZETO R, ARAI K, YAMAHA E (2008). Xenogenesis in teleost fish through generation of germ-line chimeras by single primordial germ cell transplantation. Biol Reprod 78: 159-166.

SAITO T, GOTO-KAZETO R, FUJIMOTO T, KAWAKAMI Y, ARAI K, YAMAHA E (2011) Inter-species transplantation and migration of primordial germ cells in cyprinid fish. Int J Dev Biol 55: (doi: 10.1387/ijdb.103111ts)

SHIGENOBU S, ARITA K, KITADATE Y, NODA C, KOBAYASHI S (2006). Isolation of germline cells from Drosophila embryos by flow cytometry. Dev Growth Differ 48: 49-57.

TAKEUCHI Y, YOSHIZAKI G, TAKEUCHI Y, TAKEUCHI T (2002). Mass isolation of primordial germ cells from transgenic rainbow trout carrying the green fluorescent protein gene driven by the vasa gene promoter. Biol Reprod 67 1087-1092.

WEIDINGER G, WOLKE U, KÖPRUNNER M, KLINGER M, RAZ E (1999) Identification of tissues and patterning events required for distinct steps in early migration of zebrafish primordial germ cells. Development 126: 5295-5307.

YAMAHA E, MIZUNO T, MATSUSHITA K, HASEBE Y (1999). Developmental staging in goldfish during the pre-gastrula stage. Nippon Suisan Gakkaishi 65: 709-717.

YAMAHA E, USUI K, ONOZATO H, AND HAMADA K (1986). A method for dechorionation in goldfish, Carassius auratus. Bull Japan Soc Sci Fish 52: 291 298.

YAMAHA E, MIZUNO T, HASEBE Y, TAKEDA H, AND YAMAZAKI F (1998). Dorsal specification in blastoderm at the blastula stage in the gold fish, Carassius auratus. Dev Growth Differ 40: 267-275

YAMAHA E, SAITO T, GOTO-KAZETO R, ARAI K (2007). Developmental biotechnology for aquaculture, with special reference to surrogate propagation in teleost fishes. J Sea Res 58: 8-22.

YOON C, KAWAKAMI K, HOPKINS N (1997). Zebrafish vasa homologue RNA is localized to the cleavage planes of 2- and 4-cell-stage embryos and is expressed in the primordial germ cells. Development 124: 3157-3165 


\section{Further Related Reading, published previously in the Int. J. Dev. Biol.}

See our recent Special Issue Placenta edited by Joan S. Hunt and Kent L. Thornburg at: http://www.ijdb.ehu.es/web/contents. php?vol=54\&issue=2-3

In vitro germ cell differentiation during sex differentiation in a teleost fish.

Tohru Kobayashi

Int. J. Dev. Biol. (2010) 54: 105-111

Epiblast-derived stem cells in embryonic and adult tissues.

Maria P. De-Miguel, Francisco Arnalich-Montiel, Pilar Lopez-Iglesias, Alejandro Blazquez-Martinez and Manuel Nistal

Int. J. Dev. Biol. (2009) 53: 1529-1540

Primordial germ cell biology at the beginning of the XXI Century.

Massimo De Felici

Int. J. Dev. Biol. (2009) 53: 891-894

XIV Workshop on the Development and Function of Reproductive Organs.

Massimo De Felici and Rita Canipari

Int. J. Dev. Biol. (2009) 53: 883-889

Differences in embryonic pattern formation between Caenorhabditis elegans and its close parthenogenetic relative Diploscapter coronatus.

Vera Lahl, Jens Schulze and Einhard Schierenberg

Int. J. Dev. Biol. (2009) 53: 507-515

The evolution and maintenance of Hox gene clusters in vertebrates and the teleost-specific genome duplication.

Shigehiro Kuraku and Axel Meyer

Int. J. Dev. Biol. (2009) 53: 765-773

Foetal germ cells: striking the balance between pluripotency and differentiation.

Patrick Western

Int. J. Dev. Biol. (2009) 53: 393-409

Imprinting of mammalian male gametes is gene specific and does not occur at a single stage of differentiation.

María D. Boyano, Noelia Andollo, María M. Zalduendo and Juan Aréchaga

Int. J. Dev. Biol. (2008) 52: 1105-1111

The distribution and behavior of extragonadal primordial germ cells in Bax mutant mice suggest a novel origin for sacrococcygeal germ cell tumors.

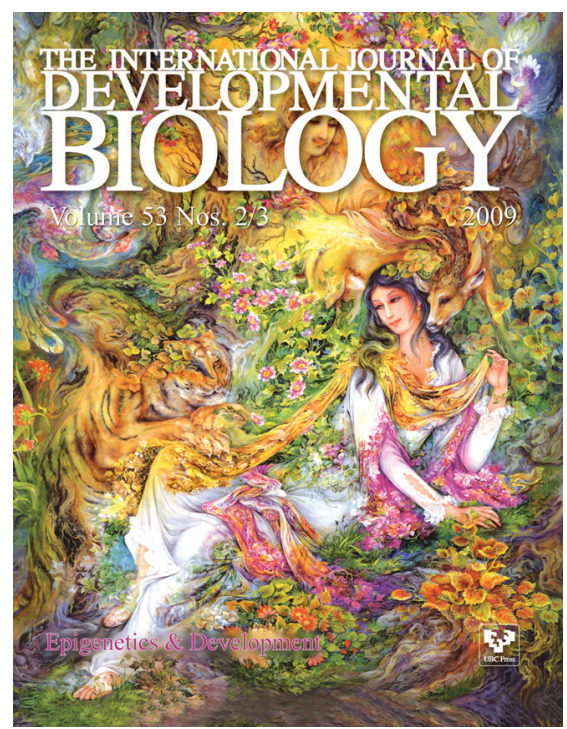

5 yr ISI Impact Factor $(2009)=3.253$

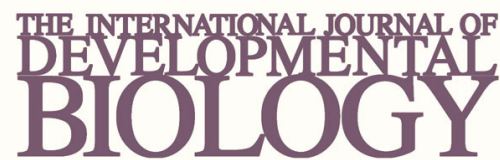

Volume 54 Nos. 6/7
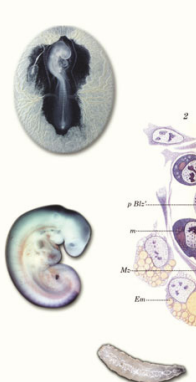

Developmental Hematopoiesis

Special Issue

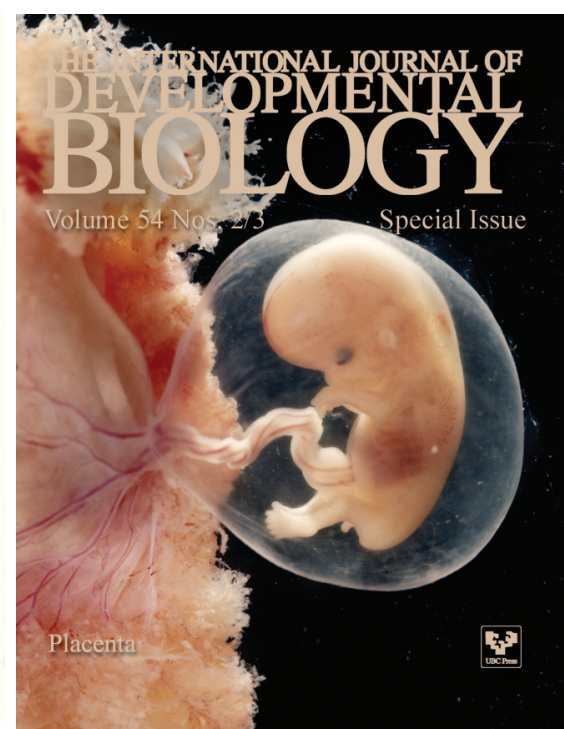

